\title{
The effect of video materials on EFL learners' oral production: A task-based approach
}

Fazilatfar, Ali Mohammad

Yazd University, Iran (afazilatfar@yahoo.com)

Mohebbi, Leila

Yazd University, Iran (Mohebbileila@ymail.com)

Modrek, Mahdi

Najfabad University- Esfahan, Iran(modrek@gmail.com

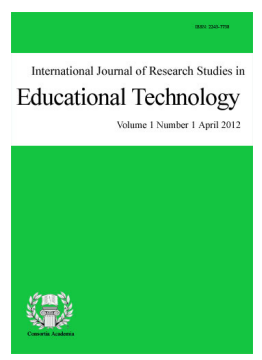

ISSN: $2243-7738$ Online ISSN: 2243-7746

OPEN ACCESS

\section{Abstract}

It has been frequently suggested that Computer Mediated Communication (CMC) can help learners improve their oral proficiency and tasks have a definite influence on the extent to which learners are engaged in negotiations. These views stimulate researcher to examine the effects of subtitled video tasks on language production of EFL learners. The present study investigated whether exposure to foreign language under different computerized task conditions had a differential impact on the improvement of learners' speaking in terms of fluency and accuracy after exposure to a curriculum with subtitled video tasks. This study was conducted on two groups each included 12 learners who were studying in Zaban Gostar language institute of Yazd. Participants were screened for their overall oral proficiency using placement test and interview then, placed at pre-intermediate level. The first group was provided with tasks without subtitle video but the second group with subtitled video tasks which they watched before doing the task. While doing the tasks, their voices were recorded and transcribed by the researcher to be analyzed. Analyzing these data showed that the learners did not produce more fluent and more accurate language when provided with the subtitled video tasks than those who were not provided with them. This study has some implications for language practitioners to design more effective materials for their language classrooms by using computerized tasks.

Keywords: Computer-Assisted Language Learning (CALL); task; subtitle; accuracy; fluency 


\section{The effect of video materials on EFL learners' oral production: A task-based approach}

\section{Introduction}

Recent years have shown a great interest in using computer as an affordable tool at homes, in schools, universities, and educational institutes. There is also widespread increase in the use of computer for foreign language learning and teaching. Getting familiar with a variety of technological, instrumental, and pedagogical developments in recent decades has made a dramatic change in the process of teaching and learning a foreign language. It has been frequently suggested that Computer Mediated Communication (CMC) can help learners improve their oral proficiency and that tasks have a definite influence on their oral production (Dooly, 2011; Rahimi \& Hosseini, 2011; Yanguas, 2010; Gunduz, 2005). Due to the lack of opportunity in foreign language setting to interact with Native Speakers (NS) the need for exposure to various kinds of scenes, situations, and accents as well as voices is important. This need can be met by audiovisual materials such as appropriate films and videotapes.

According to Carrasquillo (1994, p. 140, cited in Richards \& Renandya, 2002) audiovisual materials can provide:

$>\quad$ The motivation achieved by basing lessons on attractively informative content material,

$>\quad$ The exposure to varied range of authentic speech, with different registers, accents, intonation, rhythms, and stress,

$>\quad$ Language used in context of real situations adding relevance and interest to learning process.

In the classes in institutes, learners usually listen and repeat the conversation as a kind of practice. Sometimes, they listen to the model dialogue and repeat, add their names while practicing the model with their partner. They read a model dialogue and have a similar conversation using cues provided, listen to numbers and dates, read numbers and dates and say them and alike. Using these activities in the classroom is a kind of artificial practice and real learning does not occur. Learning to speak a foreign language requires more than knowing its grammatical and semantic rules. Learners must also acquire the knowledge of how native speakers use the language in the context of structured interpersonal exchange, in which many factors interact (Richards \& Renandya, 2002).

As Nunan (2006) mentioned among different language skills, learning to speak a foreign language seems to be much more difficult and needs much more practice in the classroom. In conversation courses, learners should be given the maximum number of opportunities to practice the target language in meaningful and collaborative situations which provides a high level of autonomy (Alavi \& Dufner, 2005). Learners should take part in tasks that require the creative and relatively unpredictable use of language that makes them to commit mistakes that should be seen as a natural part of the learning process. In English as a Foreign Language (EFL) context, there is no opportunity for learners to practice English in real contexts, and classroom does not provide such kind of interaction in a meaningful context in a way that is unpredictable for learners which also show their lack of knowledge, mistakes, and their needs.

\section{Theoretical framework}

There are several theories underlying this study which have supported the use of designed software. In this study, through integration of different skills and approaches participants have been in a situation to be able to interact naturally and discover their mistakes and needs to solve their problems. Among some theories, Long (1996) proposes a theory that supports this study. According to his theory, language is acquired as learners actively engage in attempting to communicate in the target language. It is consistent with the experimental 
The effect of video materials on EFL learners' oral production: A task-based approach

philosophy of "learning by doing". In this study acquisition can be effective because learners are engaged in tasks that push them to the limits of their current competence.

In addition to Long's interactional hypothesis, the comprehensible input hypothesis proposed by Krashen (1982) supports the view that comprehensible input is important for language learning which in this designed software the video material and instructions provide comprehensible input to the learners. It appears that acquisition would occur when learners understand messages in the target language. According to output hypothesis of Swain (1985), learning may occur through producing language either spoken or written. In this study, the oral language production is investigated. It was mentioned earlier that language production can provide the opportunity for meaningful practice of linguistic resources which leads to automaticity. Also, learners will get to improve their fluency in this way.

According to dual coding theory of Paivio (2006), verbal system and the imagery system are functionally independent and encoded by separate subsystems. In addition, bilingual situations rely on two separate verbal systems related by associative connections. In subtitled films, these three independent systems are interconnected and presented simultaneously. This may lead to better processing and recall because of the additive effect of both image and translation. Theory of second language acquisition proposed by Krashen(1982) and also Cognitive theory of multimedia learning by Mayer (1997) will support this idea. This study investigated the extent to which learners exposed to the subtitled videos included in the three computerized tasks acted better, in performing dyadic interactions, than control group that did not have access to the subtitled videos. Learners' collaborative interaction in dyads was examined by using the software designed for this study. Subtitled videos have been considered a form of pre-task.

\subsection{Research Questions}

In order to fulfill the aims of the present study, it addresses the three following research questions:

$>\quad$ Does the presentation of subtitled task videos in TBLL enhance Iranian EFL learners' fluency?

$>\quad$ Does the presentation of subtitled task videos in TBLL enhance Iranian EFL learners' accuracy?

$>\quad$ Does gender have any effect on Iranian EFL learners' fluency and accuracy in the given context?

\section{Method}

\subsection{Participants}

This study examined the oral production of 24 pre-intermediate EFL learners who were studying in a private English institute in Yazd. Their age ranged from 16 to 27. The participants were placed in pre-intermediate proficiency level based on the results of administrating a placement test and an interview.

As part of the selecting process, the participants were screened for their overall oral English proficiency using a 40-item Placement Test extracted from the placement test package of Fuscoe, Garside, and Prodromou (2006). Out of a total of 60 participants, 33 students were eligible to take part in the interview session. After scoring the interview, seven participants whose level of speaking ability did not match the others (much higher or lower than the others) were excluded from the analysis, resulting in a final sample size of 26 learners. Two raters evaluated each audio file of the interview. The evaluators were English instructors at Iran Language Institute (ILI) at the time of the experiment. The participants got a score from 1 to 25 by the raters. The relationship between the two scores assigned by the evaluators was investigated using Pearson-product moment correlation coefficient. As table (1) shows a strong positive correlation between the two variables has been found, $\mathrm{r}=.76, \mathrm{n}=24, p<.0005$. 
Fazilatfar, A. M., Mohebbi, L., \& Modrek, M.

\section{Table 1}

Inter-rater correlation of grading the interviews

\begin{tabular}{llll}
\hline & Correlations & Rater A & Rater B \\
\hline Rater A & Pearson Correlation & 1 & $.763 * *$ \\
& Sig. (2-tailed) & & .000 \\
& $\mathrm{~N}$ & 24 & 24 \\
\hline Rater B & Pearson Correlation & $.763 * *$ & 1 \\
& Sig. (2-tailed) & .000 & \\
& $\mathrm{~N}$ & 24 & 24 \\
\hline
\end{tabular}

Two of the students were chosen randomly to take part in the second pilot study. The final and main sample size of the study was composed of 24 learners (12 males and 12 females).

\subsection{Materials and instruments}

The software to provide the subjects with the materials necessary for communication was designed in IranLX studio in Isfahan. It was developed in Delphi 7.0 and was equipped with a voice recorder/player for the testing system. The sounds were edited and optimized for the software by Sound Forge 9. The voice had been done by Mrs. Peters, an American native speaker. The same process was done for the videos through Adobe Premiere Pro 7. Designing this software took around six months from July 3, 2012 to December 21, 2013 (The software is available on request on iranlx.com).

The participants were assigned to one of the two different experimental environments: a task-based environment involving the subtitled videos, and a control environment with the same task in which the students gained the same information through a computer program without the subtitled videos. Three tasks are included in this software which tested the learners according to their level of difficulty:

\section{Task number one: Compare the stadiums (sport)}

Both members of the dyads were provided with the same screen containing six stadiums, which were clickable. Upon clicking, one sport inside each building was displayed. Three of the displayed sports were the same for both members of dyads and three of them were different. Dyads were asked to identify similarities and differences between the activities occurring in the six buildings.

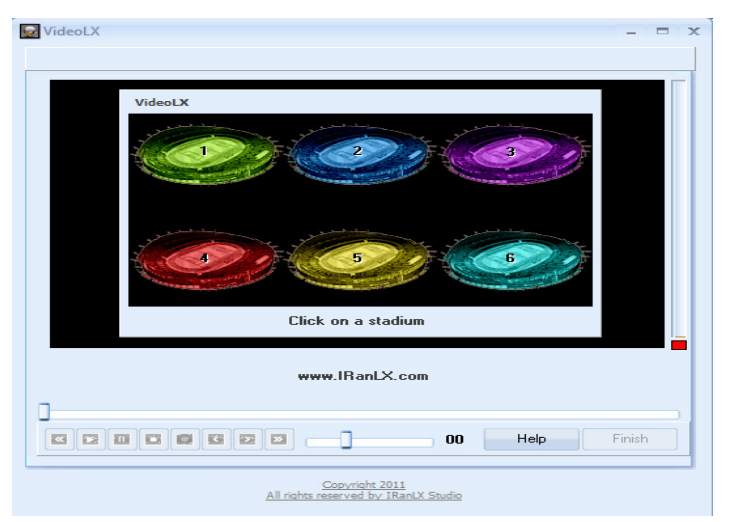

Picture 1. The main screen for task (1) 


\section{Task number two: Choosing a roommate}

Dyads were asked to decide on a roommate for sharing their house and they would stay with whom for a year. When students clicked on the name box and chose one name, the image of each volunteer and their hobbies and habits were displayed. Students were asked to decide which one could be a better roommate for them.

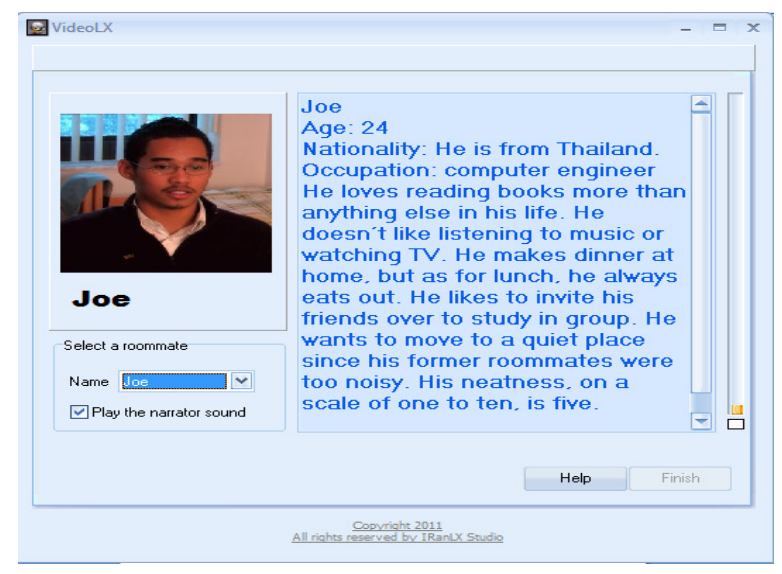

Picture 2. A sample of characteristics of roommates for task (2)

\section{Task number three: Preferred destinations (traveling)}

In this task, dyads were asked to imagine that they had decided to take a trip together during the vacation. Each member of the dyad was provided with information about attractions, hotels, activities and flight to three different cities through videos. They were asked to exchange information and decide which city to visit during vacation.

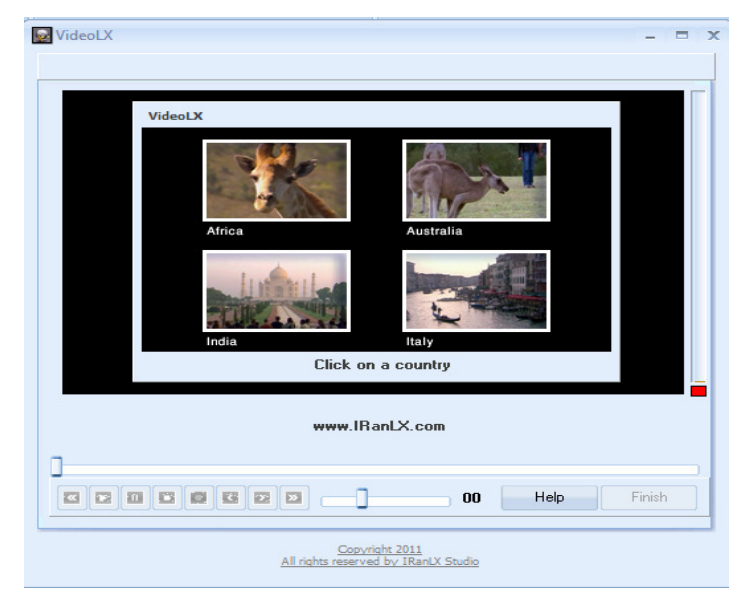

Picture 3. The main screen for task (3)

The software has two versions, one for experimental and the other for control group. In each task for the experimental group there is a subtitled video part as a pre-task which presents a short dialogue between two native English speakers engaged in a similar task, but not the same as the one students were about to complete (Table2). The videos were extracted from Fuscoe et al. (2006) published by Macmillan publication and subtitles were provided underneath the videos. The initial criterion for choosing the video clips was that they were short in length to ensure that the amount of preparation time required for watching each of the video clips into segments was not overly excessive. In addition, among the video clips selected, a range of common topics, such as sports, travelling, and choosing a roommate presented to expose learners to the everyday topics of this type. 
Fazilatfar, A. M., Mohebbi, L., \& Modrek, M.

Furthermore, the video clips consisting of a sequence of short segments were preferred, with each segment consisting of a conversation between two native speakers who had the same problem involved in the tasks accompanying audio and well-defined visual cuts between segments.

Table 2

Description of subtitled videos

\begin{tabular}{ll}
\hline \multicolumn{1}{c}{ Assigned task } & \multicolumn{1}{c}{ Topics/content of subtitled videos } \\
\hline $\begin{array}{l}\text { Preferred } \\
\text { destinations }\end{array}$ & $\begin{array}{l}\text { Two people are deciding about choosing a location for their vacation. They have a } \\
\text { specified budget and some choices. They decide about all facilities and transportation or } \\
\text { so. At last, one is winner because of having a better plan with that budget. }\end{array}$ \\
\hline $\begin{array}{l}\text { Compare the } \\
\text { stadium }\end{array}$ & $\begin{array}{l}\text { The focus is on demonstrating different sports. Two native speakers are discussing the } \\
\text { sport they like most and they say their reason for choosing that sport as the best sport. }\end{array}$ \\
\hline $\begin{array}{l}\text { Choose a } \\
\text { roommate }\end{array}$ & $\begin{array}{l}\text { Two young professional boys are looking for a third roommate because their roommate } \\
\text { found a job in another city and left them. They send an online advertisement. Then they } \\
\text { interview with three people to choose one of them as a new roommate. }\end{array}$ \\
\hline
\end{tabular}

\subsection{Data collection and procedure}

The research design of the study is a semi-experimental one because of the small and limited sample size. The available participants were randomly assigned to experimental and control groups. Two pilot studies were carried out to establish a time limit for task completion by the participants and to remove the possible problems in the procedure or the use of software package. The experimental group was given the tasks including the subtitled video but the control group was given the tasks without the subtitled video. There were three computerized tasks in the study. The participants did the tasks in pairs in the limited time given to them. Each dyad was tested individually in a quiet classroom. Before beginning the practice phase, subjects were told that they would see, hear, or simultaneously see and hear English words. They were asked to talk about the things specified in the instruction part of the software package.

A short period of instruction was given to all the students to get familiar with the software before each task. They went through a tutorial that explained how to go through the activity. This was done to give learners basic training in the application of software. The instructional intervention for both groups took place over a 5 to 10-minute instruction in Persian at the beginning of the real experimental class session along with a step by step instruction included in the software to let the students get familiar with the whole procedure and work with the software package. To ensure a consistent and parallel instruction among participants, the same instructor taught both groups. The participants were not informed about the research hypotheses or the language production variables being measured until the entire study was completed.

Each dyad met once to do three tasks. The subjects' fluency and accuracy in two groups were compared by the use of their voice transcriptions in the control and experimental groups in order to find out the impact of watching the subtitled videos on their oral production. While completing the task, learners' voice had been recorded both within the software and by means of a recorder to be transcribed. The transcripts of each of the 12 dyads were analyzed for comparison. Fluency was measured by the number of words per- minute (WPM) like what Arslanylmaz and Pedersen (2010) did. Since the students did not finish the tasks in the specific time limit defined for them, the ratio of the first 15 minutes has been considered to count the number of words per-minute. Accuracy was measured in this study through a formula proposed by Kouichi (2005): Numerical values of accuracy $=$ total number of words / (the number of errors +1 )

\subsection{Data analysis}

The quantitative analysis of each pair's dialogue records using the transcriptions aimed to establish the influence of watching subtitled video on their comprehension of the given task and on their ability to produce 
The effect of video materials on EFL learners' oral production: A task-based approach

more fluent and accurate speech. Two aspects of language use were examined to see how the participants in the two treatment conditions performed the oral task. The results of two-way between groups ANOVA are reported separately for fluency, accuracy.

Fluency - The concept of fluency shows high language proficiency (Simensen, 2010). There are different definitions for fluency such as "smooth, rapid, effortless use of language"(Crystal, 1987, p. 421, cited in Simensen, 2010) "Fluency, then, is to be regarded as natural language use" (Brumfit, 1984, p. 56, cited in Simensen, 2010), and finally language as "spoken easily and without many pauses".

Several studies of fluency have attempted to determine fluent oral use of language. They defined different approaches to assess fluency like the amount of speech over time such as the number of syllables per second (e.g., Hieke, 1985). Other aspects of speech, such as frequency and types of pauses and hesitations, have also been studied (Lennon, 1990). Arslanylmaz and Pedersen (2010); Dewaele and Pavlenko (2003); Dörnyei and Kormos (2000) used another aspect; they considered the number of words per minute (WPM) to measure the fluency. The criterion used in this study to determine the quantity of speech produced to measure the fluency of the learners was also through the number of words per minute. The number of words has been counted for each task and then added up to have the total number of words produced in each group.

For counting the words, some points have been taken into account such as, any orthographic unit bound by space, and including proper nouns and acronyms (e.g. MBA, FIFA) was counted as one word. Concatenated forms (gonna, wanna, sorta) and contracted forms (I'm, we're, they're) were counted as two words. Each number set including money units $(100 \$)$ were counted as one word. Hyphenated words (t-shirt, hip-hop, X-ray) were counted as one word. Back-channeling cues (hhhhh hh, um, oh, hey) were not counted as a word when they were not supplied in response to explicit requests for feedback as opposed to when they were part of a turn for which they were counted as a word. Repetitions in an attempt to correct a lexical error were counted as one word (e.g., I like playing very much but I... I can't; because it's boring... Boring and it's not good).

The number of words was counted for each task separately. Time limit had been defined for the study but some of the students talked much more than the limited time and it was not possible to cut it out. But some others finished the tasks earlier than 20 minutes. In order to have the number of word in a limited time, a ratio was taken to have the number of words in 15 minutes. As table (3) displays, a two-way between groups ANOVA was conducted to explore the impact of gender and watching subtitled videos on the number of words produced by the learners. The subjects were divided into two groups, control and experimental. The interaction between gender and group was not statistically significant, $\mathrm{F}(1,32)=.052, p=.82$. There was no significant main effect for group variable, $\mathrm{F}(1,32)=.97, p=.33$. However, the effect size was small (i.e. partial eta square $=.03$ ).

Table 3

Tests of Between-Subjects Effects to Investigate Fluency Dependent Variable

\begin{tabular}{ccccccl}
\hline $\begin{array}{c}\text { Partial Eta } \\
\text { Squared }\end{array}$ & Sig. & F & Mean Square & df & $\begin{array}{c}\text { Type III Sum } \\
\text { of Squares }\end{array}$ & Source \\
\hline .031 & .794 & .343 & 12604.82 & 3 & 37814.46 & Corrected Model \\
.950 & .000 & 610.64 & 2.24 & 1 & 2.24 & Intercept \\
.029 & .332 & .971 & 35673.53 & 1 & 35673.53 & group \\
.000 & .939 & .006 & 215.40 & 1 & 215.40 & sex \\
.002 & .820 & .052 & 1925.53 & 1 & 1925.53 & group * sex \\
& & & 36754.27 & 32 & 1176136.18 & Error \\
& & & & 36 & 2.37 & Total \\
\end{tabular}


Fazilatfar, A. M., Mohebbi, L., \& Modrek, M.

Accuracy - The measurement of accuracy chosen for this study is taken from the article written by Kouichi (2005).All the transcriptions of the spoken data were checked by three English teachers; two males, and a female TEFL teacher. All of them were teaching English at English institutes in Yazd when the experiment was conducted. As a first step, all the grammatical errors found by at least one teacher were investigated. Among them, errors taught as misuses at school and errors checked by more than two teachers were considered to be inaccurate and used as variables to define accuracy. In order to show numerical values of accuracy, the frequency of errors was calculated using the following formula: Numerical values of accuracy $=$ total number of words / (the number of errors+1). The larger the number is, the greater the sample's accuracy is.

A two-way between groups analysis of variance was conducted to explore the impact of gender and watching subtitled videos on learners' accuracy. As table (4) shows the interaction between gender and group was not significant, F $(1,32)=2.18, p=.015, \mathrm{~F}(1,32)=3.28, p=.07$. Leven's Sig. level was .01 that was below .05 suggesting that the variance of the dependent variable across the groups was not equal. The interaction between group and gender was not statistically significant, because the Sig. value .1 was more than .05. Results showed that there was not any difference between control and experimental group or between males and females in producing the accurate language.

\section{Table 4}

Tests of Between-Subjects Effects to Investigate Accuracy

\begin{tabular}{ccccccl}
\hline $\begin{array}{c}\text { Partial Eta } \\
\text { Squared }\end{array}$ & Sig. & F & Mean Square & df & Type III Sum of & Squares \\
\hline .164 & .121 & 2.09 & 115.02 & 3 & 345.05 & Corrected Model \\
.896 & .000 & 276.82 & 15225.77 & 1 & 15225.77 & Intercept \\
.093 & .079 & 3.29 & 180.82 & 1 & 180.82 & group \\
.024 & .379 & .80 & 43.86 & 1 & 43.86 & sex \\
.064 & .149 & 2.19 & 120.37 & 1 & 120.37 & group * sex \\
& & & 55.00 & 32 & 1760.10 & Error \\
& & & & 36 & 17330.91 & Total \\
\hline
\end{tabular}

Note. $\mathrm{R}$ Squared $=.164$ (Adjusted R Squared $=.086)$

\section{Discussion and Conclusion}

The primary aim of this study was to focus on the effect of subtitled video materials on EFL learners' oral production in a task based environment using three computer tasks designed for this study. The data were analyzed by means of two-way between groups ANOVA for each research question to test the hypotheses. The experimental groups' statistical results demonstrate that exposure to subtitled video under this computerized tasks does not result in a significant difference between the control and experimental group regarding the research variables. However, overall observation of learners' interaction through these tasks was satisfactory. They were speaking as though they were in real environment, discussing with each other. In the cases that they had opposite opinions, they were trying to convince each other. All the conditions in real situations appeared to be in this context. There were breakdowns in conversations, which led them to request for clarification. They became aware of their lack of knowledge in the cases that they could not express themselves; in other words, through these tasks they faced their limits of competence. So, they became aware of their pitfalls and tried to remove them.

The result of present study seems to confirm the result of the study done by Haghighi tafti (2004) as the learners interact much better than they do in traditional regular classes. And it also supported Rahimi and Hosseini (2011) study, since all of learners had positive attitudes toward using this technology. However, these 
indicative results do not conform to Arsylanlimaz and Pedersen (2010) findings obtained in similar experimental conditions. As it was mentioned in methodology, three tasks are being tackled at the same time; the performance of the first task is unaffected by task overlap, but the performance of the second task is impaired when presented within a few hundred seconds of the first. So there should be an interval between the two tasks, watching the video and pair interaction, that is called Psychological refractory period. The study done by Arsylanlimaz and Pedersen (2010) did not consider this issue, and maybe the difference in results is somehow related to this point.

One of the major advantages of the strategy used in this research study is the technological support that makes it possible to use it in both, face to face and distance learning environments. The novel character of these activities is expected to highly increase the students' motivation and participation. This study used the computer technology in order to make the best use of videos and subtitles to enhance the students' language learning motivation and skills in general, and listening-speaking in particular. Although watching the subtitled video did not have a significant effect on students fluency and accuracy, it is an undeniable fact that video is of a language material type that enables students to practice what they have learned through various techniques. Material designers need to assess critically the features and characteristics of the use of video and technology in classrooms, the need and objectives of the courses, and then develop some technological tools that fit their pedagogical purpose. It should be acknowledged that the research was conducted under some limitations. Results from this study should be taken cautiously due to these limitations. One of these is the small sample size of participants.

The findings of this study also revealed that students showed much more motivation in using these kinds of tasks for improving their speaking skills. In the EFL conversation classes, these kinds of natural practice of language are not usually provided. Students are asked to talk about a place to choose for their vacation, but they are not given some clues and information to discuss. However, in the present syllabus, the researchers provided all these opportunities for learners. Besides, the study set out to examine EFL learners' collaborative dialogue motivated by collaborative tasks and its effect on language learning in the computer-mediated learning environment. There are several pedagogical implications of the study. This research might provide useful insights for EFL teachers and those responsible for curriculum development.

Through the integration of CALL into course syllabi, EFL teachers can create a supportive learning, in which learners interact with each other for meaningful purposes. Teachers can enhance students' motivation by helping students gain knowledge and skill of using computers, giving them ample opportunities to use electronic communication, and carefully integrating computer activities into the regular structures and goals of the course (Warschauer, 1996). Providing such kinds of software packages helps to make the use of Computer Supported Communication Learning (CSCL) more and more commonplace in language learning classrooms; this has given rise to the need for more research on roles and processes of CSCL in language teaching and learning and how such kind of interactions are different from online or traditional face-to-face classroom activities.

The development of future similar empirical studies along with such theoretical frameworks appears to be promising for studies on FL teaching pedagogy. Future research should investigate the comparison across different pairs. The impact of proficiency differences on language learning in the CALL context will also be an interesting issue to explore. The findings of the present study can have implications not only for the teachers and learners, but also for material preparation experts. The selection and implementation of the appropriate kind of software package can have a considerable effect on oral production of EFL learners.

Acknowledgement - This article was presented at the $1^{\text {st }}$ conference on English Language Studies held at Azarbaijan Shahid Madani University, Tabriz, Iran (30-31 October 2012). A paper entitled "subtitled task videos and their effects on EFL language production" was also presented as a poster at the $10^{\text {th }}$ International TELLSI Conference held at Shahid Beheshti University, Tehran, Iran (16-19 October 2012). 


\section{References}

Alavi, M., \& Dufner, D. (2005). Technology-mediated collaborative learning: A research perspective. In S. R. Hiltz \& R. Goldman (Eds.), Learning together online: Research on asynchronous learning networks (pp. 191-213). Mahwah, NJ: Lawrence Erlbaum.

Arslanylmaz, A., \& Pedersen, S. (2010). Improving language production using subtitled similar task videos. Language Teaching Research, 14(4), 377-395. http://dx.doi.org/10.1177/1362168810375363

Dewaele, J.-M., \& Pavlenko, A. (2003). Productivity and lexical diversity in native and nonnative speech: a study of cross cultural effect. In V. Cook (Ed.), Effects of second language on the first (pp. 120-141). Clevedon, UK: multilingual matters.

Dooly, M. (2011). Divergent Perceptions of tele-collaborative language learning tasks: Task as work plan vs. Task as process. Language Learning \&Technology Journal, 15(2), 69-91.

Dornyei, Z., \& Kormos, J. (2000). The role of individual and social variables in task performance. Language Teaching Research, 4, 275-300. http://dx.doi.org/10.1177/136216880000400305

Fuscoe, K., Garside, B., \& Prodromou, L. (2006). Attitude: Everyday English language reference guide. Macmillan publication.

Gündüz, N. (2005). Computer Assisted Language Learning (CALL). Journal of Language and Linguistic Studies, 1(2), 193-214.

Haghighi Tafti, I. (2004). The effect of task-based instruction on speaking skill of Iranian EFL learners. Unpublished Masteral thesis, Khatam University, Tehran, Iran.

Hieke, A. E. (1985). A componential approach to oral fluency evaluation. Modern Language Journal, 69, 135-142. http://dx.doi.org/10.1111/j.1540-4781.1985.tb01930.x

Kouichi, A. (2005). Japanese English: Fluency and accuracy in the spoken English of high school learners. Retrieved from http://www.waseda.jp/ocw/AsianStudies/9A77WorldEnglish_Spring2005/Lecture_Notes/13_Japan_/Ja panese_English_High_School_Ano.pdf

Krashen, S. D. (1982). Principles and practice in second language acquisition. Oxford: Pergamon Press.

Lennon, P. (1990). Investigating fluency in EFL: A quantitative approach. Language Learning, 40, 387-412. http://dx.doi.org/10.1111/j.1467-1770.1990.tb00669.x

Long, M. (1996). The role of linguistic environment in second language acquisition. In W. C. Ritchie \& T. K. Bhatia (Eds.), Handbook of second language acquisition (pp. 413-468). New York: Academic Press. http://dx.doi.org/10.1016/b978-012589042-7/50015-3

Mayer, R. E. (1997). Multimedia learning: Are we asking the right questions. Educational Psychologist, 32, 1-19. http://dx.doi.org/10.1207/s15326985ep3201_1

Nunan, D. (2006). Second language teaching and learning. Boston: Heinle \& Heinle Publishers.

Paivio, A. (2006). Dual coding theory and education. Retrieved from http://www.umich.edu/ rdytolrn/pathwaysconference/.../paivio.pdf

Rahimi, M., \& Hosseini, S. F. (2011). The impact of computer-based activities on Iranian high-school students' attitudes towards computer-assisted language learning. Procedia Computer Science, 3, 183-190. http://dx.doi.org/10.1016/j.procs.2010.12.031

Richards, J. C., \& Rennandya, W. A. (2002). Methodology in language teaching (1st ed.). Cambridge: Cambridge University Press. http://dx.doi.org/10.1017/CBO9780511667190

Simensen, A. M. (2010). Fluency: an aim in teaching and a criterion in assessment. Acta Didactica Norge, 4(1), $1-13$.

Swain, M. (1985). Communicative competence: Some roles of comprehensible input in its development. In S. M. Gass \& C.G. Madden, (Eds.), Input in second language acquisition (pp. 235-253). Rowley, MA: Newbury House.

Yanguas, I. (2010). Oral computer- mediated interaction between L2 learners: It's about time! Language Learning \& Technology, 14(3), 72-93. 